\title{
Modelling and design analyses of a piezoelectric cymbal transducer (PCT) structure for energy harvesting application
}

\author{
H. G. Chua, B. C. Kok \& H. H. Goh \\ Department of Electrical Power, \\ Faculty of Electrical and Electronic Engineering, \\ Universiti Tun Hussein Onn Malaysia (UTHM), Malaysia
}

\begin{abstract}
The piezoelectric cymbal transducer (PCT) is auspiciously identified as the best design for piezoelectric energy harvesting, particularly in high stress conditions. It is designed to harvest the ambient mechanical stress and vibration that ubiquitously exist in our environment into electrical energy. In this paper, a PCT structure is examined for its energy harvesting capabilities in both, mechanical and electrical environment using COMSOL FEA (Finite Element Analysis) simulation software. The PCT design structure comprises of piezoelectric disk slotted in between two dome-shaped metal end caps and slip rings. The shallow cavity depth allows the mechanical force to magnify the distributed circumferential force on the piezoelectric disk. A load resistor is introduced to the finite element method (FEM) via PSPICE netlist as to calculate the harvested power of the PCT. It has been discovered that the different metal end caps materials, the dimension of the piezoelectric disk and end caps with various electrical resistive load had significant corresponding effects on the power generation of the PCT. A total generated power of $0.46 \mathrm{~mW}$ has been obtained from a PCT dimension of $32 \mathrm{~mm}$ diameter wide along with a 0.3 thickness end cap under a $50 \mathrm{~N}$ force across $3 \mathrm{M} \Omega$ load resistance.

Keywords: piezoelectric energy harvesting, cymbal transducer, PZT (Lead Zirconate Titanate).
\end{abstract}




\section{Introduction}

Wasted or unused energy harvesting is a popular topic due to its continuous growth in research, studies and effort to obtain clean and efficient energy sources. It is a process of extracting the unused energy from the ambient environment into a usable electrical energy. An example of unused energy which exists in the ambient environment is vibrations that can be found in human motion, moving vehicle, flowing water, wind and shock waves. Among these phenomenal existences, a continuous flow of moving vehicle that causes stress, strain, deformation and vibration in roadways are the most promising sources for energy harvesting. In less than a decade, energy harvesting research related to high stress and ambient vibration using piezoelectric technology have been studied. Piezoelectric cymbal transducer (PCT) is one of the potential piezoelectric structures as an energy harvesting application due to its well-known capability to convert stress and vibration into electricity [1].

In this paper, the general idea of the PCT energy harvester is proposed to embed in roadways pavements. The purpose for selecting such application is that the PCT structure has reasonable efficiency, high durability under massive load, medium stiffness and low cost [2]. Thus, PCT provide a potential option for energy harvesting under high stress environment such as roadways pavements. Based on Table 1, PCT is not a new design structure as it has been used in various applications such as actuators. Various parameter studies relating to the PCT design structure have been examined especially in the physical aspect such as resonance behaviour and mechanical stress conditions [3].

Kim et al. [4], investigated the PCT performance for each various PZT (Lead Zirconate Titanate) materials (soft, hard and high piezoelectric voltage, $g$ ). Among the three fabricated materials, the high-g material generates higher open circuit peak voltage when it is placed in the cymbal transducer under $7.8 \mathrm{~N}$ cyclic force at $100 \mathrm{~Hz}$ frequency [4]. Furthermore in Kim et al.'s following research papers [5], they persisted to examine the PCT structure for energy harvesting under high pre-stressed force at cyclic vibration $(100-200 \mathrm{~Hz})$ with different thickness for each PZT and metal end-caps. Based on their findings, evaluation and improvement, the PZT thickness of $1 \mathrm{~mm}$ along with the metal end cap of $0.4 \mathrm{~mm}$ thickness amplifies the power output generation, as 0.75 times higher compared to the initial prototype with $0.3 \mathrm{~mm}$ metal end cap. Yuan et al. [6] improved the energy harvesting of the PCT structure by introducing fringes and cones on the metal end cap slotted-cymbal transducer which is expected to curb the circumferential stress and increase the energy transmission coefficient during flexural motions. They remarked that 18 cone radial slot has increased 0.6 times more output power compare to fringe radial slot.

Besides experimental works, finite element method (FEM) simulation plays a vital role on PCT design evaluation as it provides users to understand about the PCT performance by tweaking the several physical parameters according to what needs to be studied. Zhao et al. [2] studied and examined the PCT structure by evaluating the physical parameters such as diameter, cavity base diameter and piezoceramic thickness using finite element analysis (FEA) method. They reported 
that the increase diameter of the cymbal transducer and cavity base amplifies the potential electric energy and linearly decrease its mechanical to electrical conversion efficiency.

Daniels et al. [3] investigated several PCT physical parameters and validated the design using finite element model that comprise of both mechanical and electrical characteristics for non-resonant energy harvesting application. Based on their distinctive research findings, wider angle of the metal end cap decreases the power output generation of the PCT. Leinonen et al. [7] examined the combine electrical and electromechanical of the convex shaped PCT energy harvester during walking for both approaches using FEM simulation and actual prototype testing, respectively. They remarked that their unique convex shaped PCT prototype was able to generate $104 \mathrm{~mW}$ output power more compared to Kim et al. [5] under the same force magnitude and frequency.

Table 1: Various PCT based energy harvesting research.

\begin{tabular}{|c|c|c|c|c|c|}
\hline Authors & Approach & $\begin{array}{l}\text { Frequency } \\
\text { range } \\
(\mathrm{Hz})\end{array}$ & Dimension & Power/energy & $\begin{array}{l}\text { Electrical } \\
\text { related } \\
\text { output } \\
\text { studies }\end{array}$ \\
\hline $\begin{array}{l}\text { Kim et al. [4], } \\
\text { (2004) }\end{array}$ & Experiment & $50-150$ & $\begin{array}{l}29 \mathrm{~mm} \text { diameter, } \\
1 \mathrm{~mm} \text { thickness, } \\
0.3 \mathrm{~mm} \text { steel end } \\
\text { cap }\end{array}$ & $39 \mathrm{~mW}$ & Power \\
\hline $\begin{array}{c}\text { Kim et al. }[5], \\
(2005)\end{array}$ & $\begin{array}{c}\text { Experiment } \\
\text { and } \\
\text { FEM } \\
\text { simulation } \\
\end{array}$ & $100-200$ & $\begin{array}{l}29 \mathrm{~mm} \text { diameter, } \\
1 \mathrm{~mm} \text { thickness, } \\
0.4 \mathrm{~mm} \text { steel end } \\
\text { cap }\end{array}$ & $52 \mathrm{~mW}$ & Power \\
\hline $\begin{array}{l}\text { Yuan et al. } \\
\text { [6], (2009) }\end{array}$ & Experiment & 120 & $\begin{array}{c}35 \text { diameter, } \\
2 \mathrm{~mm} \text { thickness, } \\
0.5 \mathrm{~mm} \text { Cone- } \\
\text { slotted } \\
\text { Phosphor-bronze } \\
\text { end cap }\end{array}$ & $16 \mathrm{~mW}$ & Power \\
\hline $\begin{array}{l}\text { Zhao et al. }[2] \text {, } \\
\text { (2010) }\end{array}$ & $\begin{array}{c}\text { FEM } \\
\text { simulation }\end{array}$ & 20 & $\begin{array}{l}32 \mathrm{~mm} \text { diameter, } \\
2 \mathrm{~mm} \text { thickness, } \\
0.3 \mathrm{~mm} \text { steel end } \\
\text { cap }\end{array}$ & $\begin{array}{c}0.06 \mathrm{~J} \\
\text { approximate } \\
1.2 \mathrm{~mW} \text { at } 20 \mathrm{~Hz} \\
\text { vehicle load } \\
\text { frequency }\end{array}$ & $\begin{array}{l}\text { Joule and } \\
\text { Electrical } \\
\text { Potential }\end{array}$ \\
\hline $\begin{array}{l}\text { Daniels et al. } \\
\text { [3], (2013) }\end{array}$ & $\begin{array}{l}\text { Experiment } \\
\text { and } \\
\text { FEM } \\
\text { simulation }\end{array}$ & $2-5$ & $\begin{array}{c}\text { 30mm diameter. } \\
0.75-1 \mathrm{~mm}, \\
\text { thickness, } \\
0.33 \mathrm{~mm} \\
\text { thickness }\end{array}$ & $0.07 \mathrm{~mW}$ & Power \\
\hline $\begin{array}{l}\text { Leinonen et al. } \\
\text { [7], (2014) }\end{array}$ & $\begin{array}{l}\text { Experiment } \\
\text { and } \\
\text { FEM } \\
\text { simulation }\end{array}$ & $1-5$ & $\begin{array}{c}35 \mathrm{~mm} \text { diameter, } \\
0.5 \mathrm{~mm} \\
\text { thickness, } \\
0.25 \mathrm{~mm} \text { steel } \\
\text { end cap } \\
\end{array}$ & $\begin{array}{c}175 \mu \mathrm{W} \text { from } \\
\text { FEM } \\
\text { simulation, } 250 \\
\mu \mathrm{W} \text { actual } \\
\text { prototype. }\end{array}$ & Power \\
\hline
\end{tabular}

Apart from the actual PCT design, there are several methods that can aid the understanding of piezoelectric behaviours. Equivalent circuit method characterises the fundamental concept of both mechanical and electrical elements 
of the system. However, this approach does not imply for analytical modelling approach which include more mechanical aspects that requires complicated mathematical calculation and complex computation for non-resonance modelling states. Besides that, designing a good performance PCT structure for energy harvesting requires an essential understanding and agreement for the interdependency relation between electrical and mechanical behaviour. The key point for energy harvesting characteristics is its impedance as it is an important parameter when designing electrically efficient circuit for the management and utilisation of the power harvested in a practical application [3].

This aim of this paper is to investigate and examine the physical parameter of the PCT structures, both electromechanical and electrical using FEA simulation integrated with PSPICE netlist environment. Therefore, these offer the advantage and enable the PCT researchers to explore the various physical conditions and the electrical load resistance corresponding to determine the maximum power output [3]. The paper is arranged as follows: the PCT design description. Then the piezoelectric effect is explained in Section 3. The respective Section 4 and Section 5 will elaborate on the simulation modelling of the PCT and design analysis, respectively. In Section 6, the conclusion and future works of the PCT modelling is explained.

\section{PCT design descriptions}

Piezoelectric cymbal transducer (PCT) are ceramic metal composite flex tensional transducers which allow the flexural vibration on the metal cap to be absorbed and simultaneously incurs extension or contraction vibration onto the piezoelectric element. It comprises of a poled piezoelectric disk (fully electrodes on top and bottom surface) which is sandwich with both truncated cone-shaped metal end caps, each containing a shallow air-filled cavity on their inner surface [1-3] as shown in Fig. 1.

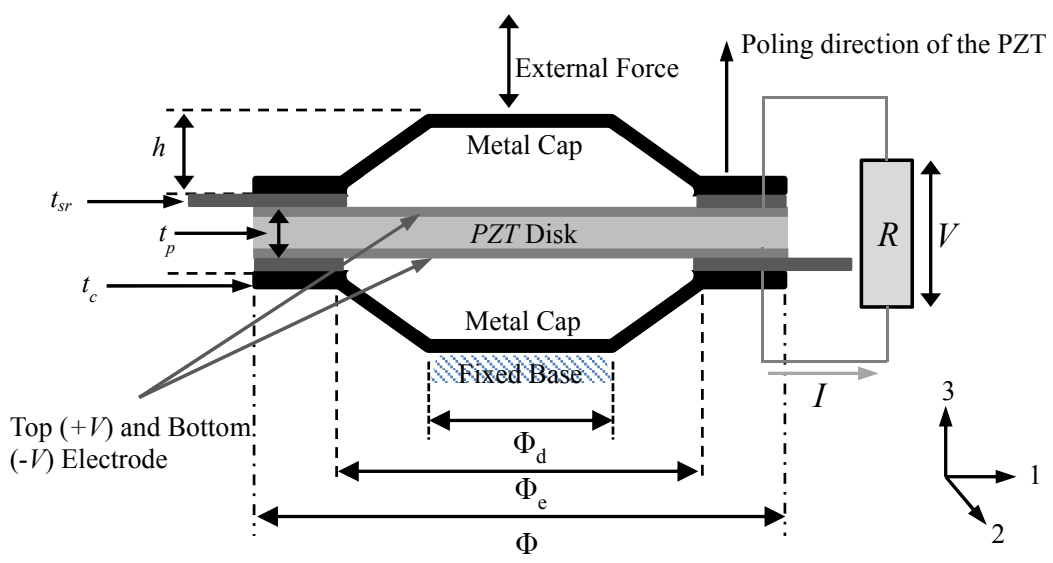

Figure 1: Piezoelectric Cymbal Transducer (PCT). 
The cavity design allows the cone-shaped metal end caps to act as mechanical transformers for transforming and amplifying a portion of the incident axialdirection stress into tangential and radial stresses of the opposite sign. Moreover, the metal end caps magnify the circumferential force onto the piezoelectric disk and increases the elastic strain energy stored in the piezoelectric disk for energy harvesting [3]. A PZT ceramics piezoelectric material has been used in this research project. Table 2 illustrates the geometric properties for the PCT structure in which corresponding to the design illustration as depicted in Fig. 1.

Table 2: Dimension parameter of PCT.

\begin{tabular}{|l|c|c|}
\hline \multicolumn{1}{|c|}{ Parameter } & Dimension & Measurement $(\mathrm{mm})$ \\
\hline Total diameter $(\mathrm{mm})$ & $\Phi$ & 32 \\
\hline Cavity base diameter $(\mathrm{mm})$ & $\Phi_{e}$ & 22 \\
\hline Apex/End cap diameter $(\mathrm{mm})$ & $\Phi_{d}$ & 10 \\
\hline $\begin{array}{l}\text { Piezoceramic (PZT) thickness } \\
(\mathrm{mm})\end{array}$ & $t_{p}$ & 0.3 \\
\hline Cavity height $(\mathrm{mm})$ & $h$ & 2 \\
\hline End cap thickness $(\mathrm{mm})$ & $t_{c}$ & 0.3 \\
\hline Slip ring thickness $(\mathrm{mm})$ & $t_{s r}$ & 0.015 \\
\hline
\end{tabular}

\section{Theoretical background}

\subsection{Piezoelectric effects}

Piezoelectric generates electric field based on an applied mechanical stress. This phenomenon is called piezoelectricity or direct piezoelectric effect. However when external voltage is applied on the piezoelectric material, it will cause deformation or strain on the piezoelectric material itself. Thus, this phenomenon is called inverse or converse piezoelectric effect. The general constitutive equation of the piezoelectric direct and inverse effect can be described as the following [2]:

$$
\begin{gathered}
S_{i}=s_{i j}^{E} T+d_{m i} E_{m} \\
D_{m}=d_{m i} T_{i}+\varepsilon_{m k}^{T} E_{k}
\end{gathered}
$$

where, $i, j=1,2,3 \ldots .6: m, k=1,2,3: T$ is the stress, $D$ is the electric displacement, $S$ is the strain and $E$ is the electric field, $\varepsilon^{T}$ is the permittivity measured at constant stress, $d$ is the piezoelectric constant and $s^{E}$ is the compliance measured at constant electric field.

\subsection{Mathematical analysis of the cymbal transducer}

In PCT based energy harvesting application, only direct piezoelectric effect is considered where the external electric field is zero. In the 3rd axial direction, the corresponding vertical force causes the polarisation, $\mathrm{P}_{3}$ to appear on the vertical surface of the PZT [2]. Thus, eqn. (2) can be rewritten as eqn. (3), 


$$
P_{3}=\sum_{i=1}^{6} d_{3 i} T_{i}
$$

where, $\mathrm{P}_{3}$ is the piezoelectric polarisation at $3 \mathrm{rd}$ direction as the magnitude is equal to the charge density at the applied surface, $\mathrm{d}_{3 \mathrm{i}}$ is the piezoelectric constant and $\mathrm{T}_{\mathrm{i}}$ is the stress tensor.

The polarisation generates an internal electric field in PZT [2]:

$$
E_{3}=\frac{P_{3}}{\varepsilon_{33}^{T}}
$$

or

$$
E_{3}=\sum_{i=1}^{6} g_{3 i} T_{i}
$$

where, $\mathrm{E}_{3}$ is the internal electric field in the PZT, $\mathrm{g}_{3 \mathrm{i}}$ is the piezoelectric voltage constant of PZT and $\varepsilon_{33}^{T}$ is the relative dielectric constant in 3rd direction.

The relation between piezoelectric voltage coefficient, $g_{3 i}$ and piezoelectric constant, $\mathrm{d}_{3 \mathrm{i}}$ is given as [2]:

$$
g_{3 i}=\frac{d_{3 i}}{\varepsilon_{o} \varepsilon_{33}^{T}}
$$

where $\varepsilon_{0}$ is the dielectric constant of vacuum. The stress tensor on the PZT is due to the vertical force on the 3rd axial direction. Thus, it generates open circuit voltage (V) on the PZT which can be calculated from eqn. (3) and is given as [2]:

$$
V_{3}=\int E_{3} d t_{p}=\sum_{i=1}^{6} \int g_{3 i} T_{i} d t_{p}
$$

where $\mathrm{V}_{3}$ is the electric potential (voltage) at the 3rd direction caused by the polarisation changing, which can be obtained through FEA and $t_{p}$ is the PZT thickness.

The output electric energy of the PCT structure based energy harvesting can be calculated using eqn. (8) [2]:

$$
U_{E}=\frac{1}{2} P_{3} E_{3} A t_{p}=\frac{1}{2} V^{2} \frac{\varepsilon_{33}^{T} \varepsilon_{o} A}{t_{p}}
$$

where $\mathrm{U}_{\mathrm{E}}$ is the stored electric energy and A is the surface area of the PZT disk.

\section{COMSOL modelling of the PCT structure}

The proposed PCT structure is developed using COMSOL multi-physics finite element analysis (FEA) software environment. The modelling includes the general structure of the PCT with a resistor load introduced via PSICE netlist and is connected in parallel with a piezoelectric disk of the PCT. Fig. 2 shows a section 
of 3D model and the side view of the PCT structure using COMSOL. The predefined material properties in COMSOL for the developed model of the PCT structure are illustrated in Table 3.

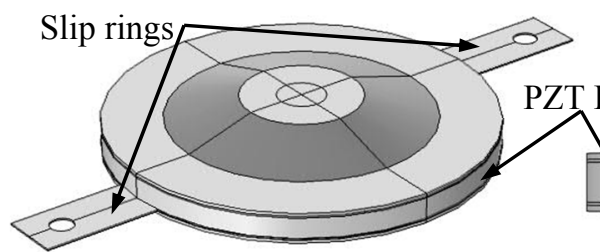

(a)

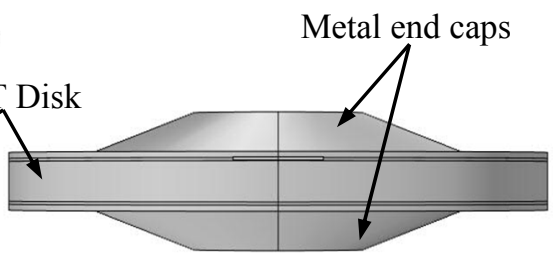

(b)

Figure 2: (a) 3D view and (b) side view of the PCT structure.

The mechanical and electrical boundary conditions are designated to the selected sections of the PCT structure. The mechanical boundary conditions for the PCT structure are set fixed at the bottom end cap cavity base while the universal distributed body load is set at the top surface along with cavity base of the upper end cap. Besides, the electrical boundary condition for the PZT material is set to ground at the bottom boundary whereas the terminal connection that interfaces with PSPICE is set on top of the boundary. All domains are meshed by free tetrahedral elements. The model is meshed with physics controlled mesh and element size fine. The simulation computes the PCT open circuit voltage along with the load resistance output voltage and power as the results are discussed in the following section.

Table 3: Material properties for simulation.

\begin{tabular}{|l|c|c|}
\hline Material properties & PZT-5H & Steel \\
\hline Young Modulus $(\mathrm{GPa})$ & - & 205 \\
\hline Poisson's ratio & - & 0.28 \\
\hline Density $\left(\mathrm{kg} / \mathrm{m}^{3}\right)$ & 7500 & 7850 \\
\hline$S_{11,21}^{E}\left(1 \times 10^{-12} \mathrm{~m}^{2} / \mathrm{N}\right)$ & 16.5 & - \\
\hline$S_{12,21}^{E}\left(1 \times 10^{-12} \mathrm{~m}^{2} / \mathrm{N}\right)$ & -4.78 & - \\
\hline$S_{13,23,31,32}^{E}\left(1 \times 10^{-12} \mathrm{~m}^{2} / \mathrm{N}\right)$ & -8.45 & - \\
\hline$S_{33}^{E}\left(1 \times 10^{-12} \mathrm{~m}^{2} / \mathrm{N}\right)$ & 20.7 & - \\
\hline$S_{44,55}^{E}\left(1 \times 10^{-12} \mathrm{~m}^{2} / \mathrm{N}\right)$ & 43.5 & - \\
\hline$S_{66}^{E}\left(1 \times 10^{-12} \mathrm{~m}^{2} / \mathrm{N}\right)$ & 42.6 & - \\
\hline$d_{31,32}\left(1 \times 10^{-12} \mathrm{C} / \mathrm{N}\right)$ & -274 & - \\
\hline$d_{33}\left(1 \times 10^{-12} \mathrm{C} / \mathrm{N}\right)$ & 593 & - \\
\hline$d_{15,24}\left(1 \times 10^{-12} \mathrm{C} / \mathrm{N}\right)$ & 741 & - \\
\hline$\varepsilon_{11,12}$ & 3130 & - \\
\hline$\varepsilon_{33}$ & 3400 & - \\
\hline
\end{tabular}




\section{Design analysis}

The evaluation of the PCT structure is carried out based on the material end cap, the end cap thickness, the thickness of the piezoelectric disk and the electrical resistive load. Therefore, the simulation results of the PCT performance are segregated and organise into 3 sections, the metal end cap material selection, steel end cap evaluation with different thickness with various load resistance and fixed metal end cap evaluation with different PZT thickness.

\subsection{Material selection of the metal end cap}

In this study, two types of metal with $0.3 \mathrm{~mm}$ thickness has been used (steel and aluminium) for the cymbal transducer end cap. These metals are evaluated based on the total displacement, electrical potential and electric energy as shown in Fig. 3 and Fig. 4, respectively.

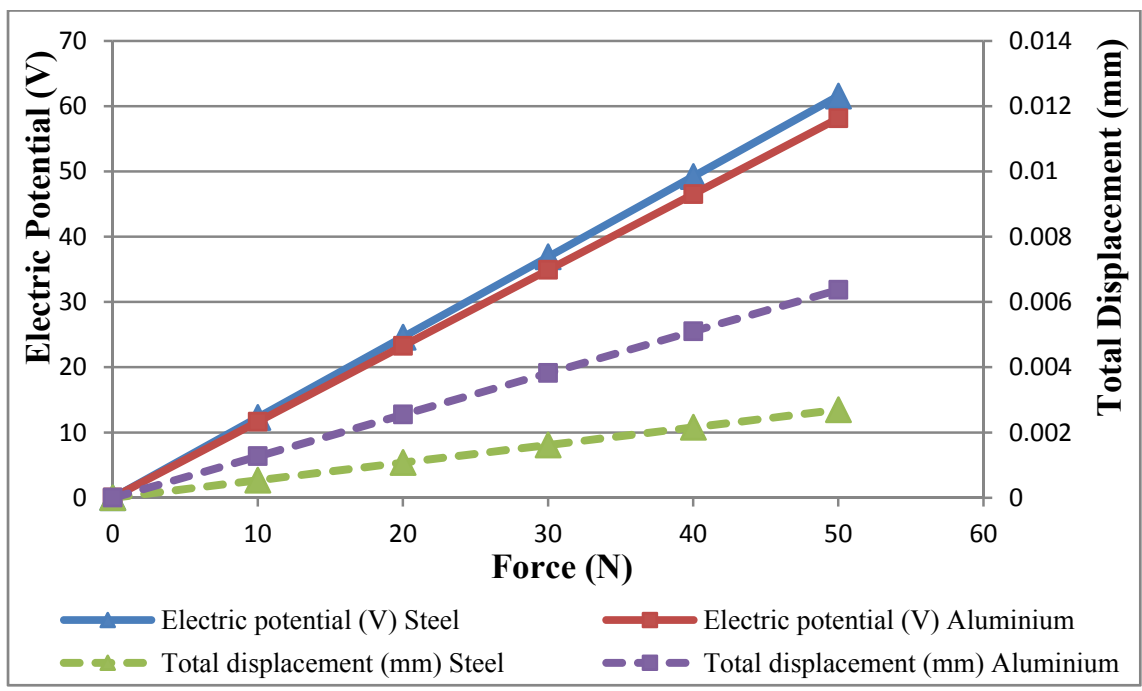

Figure 3: Electric potential (V) and total displacement (mm) under various magnitude force.

Fig. 3 illustrates the PCT that uses steel end cap generates higher open circuit electric potential under linear magnitude force compare to aluminium. This is because steel produces less displacement and has a better yield strength which capable to endure loading with higher force on the cymbal transducer compare to aluminium [4]. Using the dimension parameter and material properties from table 1 and table 2, respectively, the electric energy of the PCT with steel and aluminium end caps can be calculated using eqn. 8 [2] as shown Fig. 4. While the PCT of the electrical energy is directly proportional to the electrical potential, PCT with steel end cap amplify higher electrical energy than aluminium end cap. 


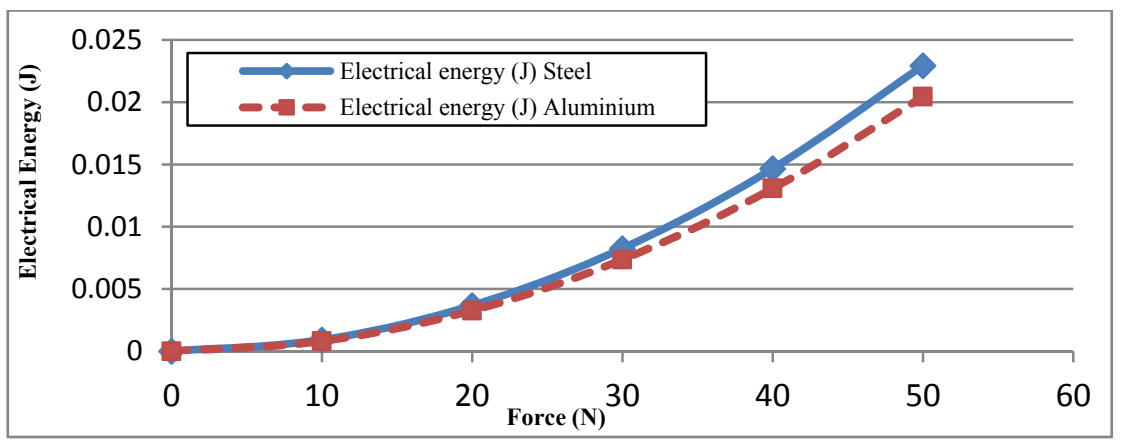

Figure 4: Electric energy generation versus magnitude force for steel and aluminium end cap.

\subsection{Evaluation of different thickness of the steel end cap with various load resistance}

The steel end cap thickness enhances the endurance of the piezoceramic to sustain higher force level in result to higher PCT output power [5]. However, the force endures by the PCT structure is limited to certain steel cap thickness. According to Kim et al. [5] investigation, steel cap with $0.3 \mathrm{~mm}$ and $0.4 \mathrm{~mm}$ thickness could not endure higher force level than $50 \mathrm{~N}$ and $70 \mathrm{~N}$, respectively. Fig. 5 and Fig. 6 illustrate the evaluation of the PCT output power generation between the cap thickness and input force level. $2 \mathrm{~mm}$ PZT thickness is used in this study and the output power is measured across $3 \mathrm{M} \Omega$ load resistance.

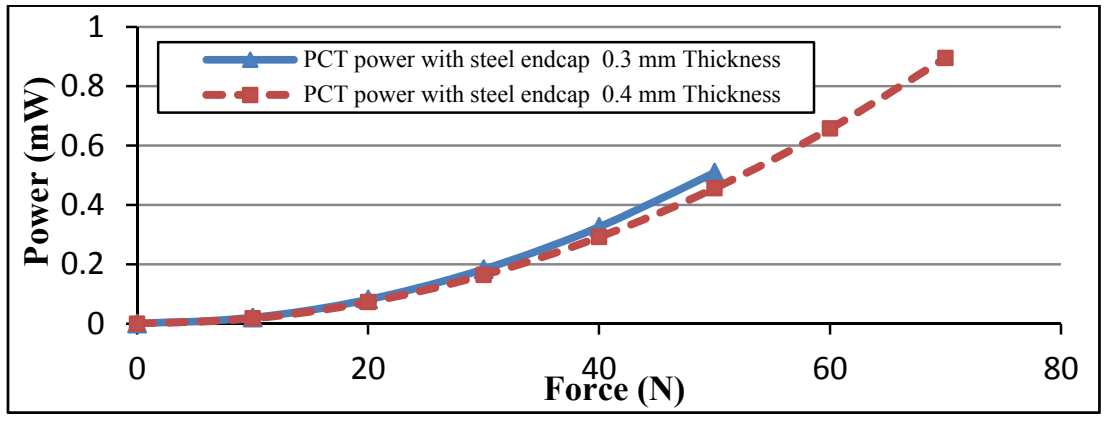

Figure 5: PCT performance for various steel end cap thickness and force level.

At identical $50 \mathrm{~N}$ force shown in Fig. 5 and Fig. 6, 0.4mm thickness generates slightly lower as compared to $0.3 \mathrm{~mm}$ thickness. Despite of this, $0.4 \mathrm{~mm}$ thickness has higher force endurance which relatively generates higher output power. Fig. 4 demonstrated that both $0.3 \mathrm{~mm}$ and $0.4 \mathrm{~mm}$ cap thickness at the highest force level could generate up to $0.5 \mathrm{~mW}$ and $0.9 \mathrm{~mW}$, respectively. Fig. 6 shows the maximum power generation of the PCT across $1 \mathrm{M} \Omega$ with various cap thickness and force. 


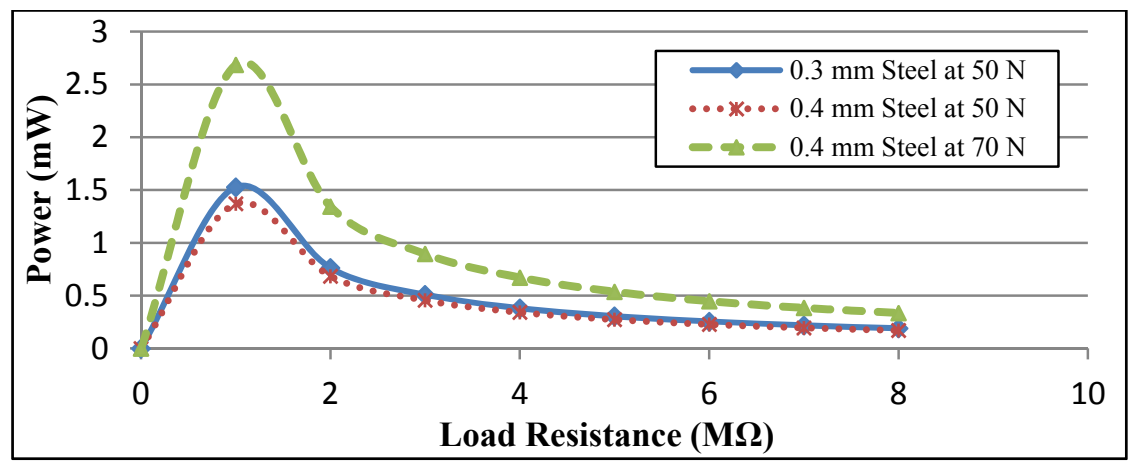

Figure 6: PCT performance for various steel thickness, force level and load resistance.

\subsection{Evaluation of different thickness of the PZT with various load resistance}

Fig. 7 and Fig. 8 show the performance of the PCT using different PZT thickness and end cap thickness. As illustrated in Fig. 7, the output power of the PCT using $3 \mathrm{~mm}$ PZT thickness is enhanced significantly as compared to $1 \mathrm{~mm}$ PZT thickness across $1 \mathrm{M} \Omega$ under $50 \mathrm{~N}$ force. Likewise in Fig. 8, the PCT power is amplified relatively twice with the increment of PZT thickness and force.

This could be explained as both the PZT thickness and rigidity increases, the trend of the PCT output power relatively enhance because the deformation of the PZT disk decreases under the same force from the metal end cap. Although the volume increases in the PZT ceramic, the distributed cyclic tangential force will not be able to penetrate in the centre of the PZT thickness [5].

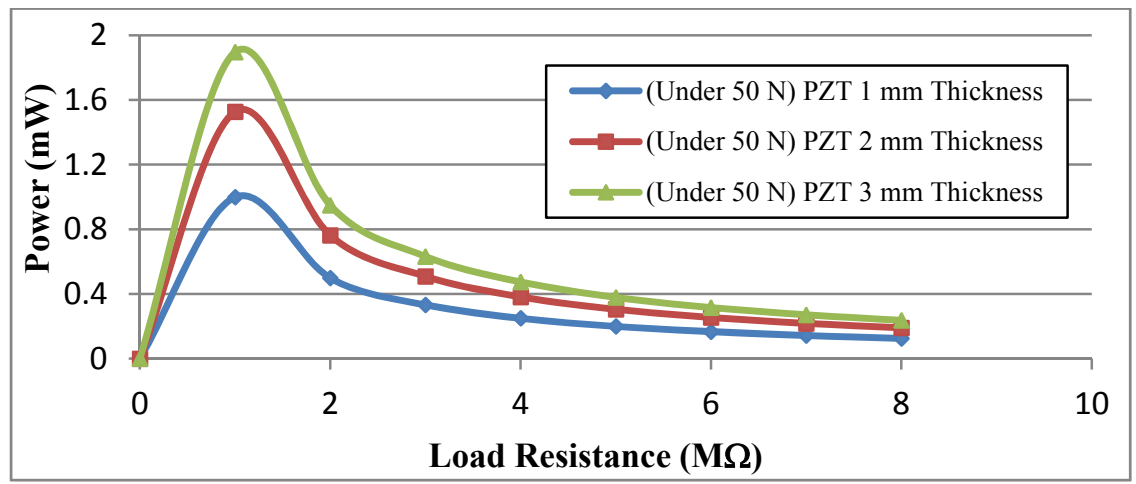

Figure 7: PCT output power with various PZT thicknesses with $0.3 \mathrm{~mm}$ end cap. 


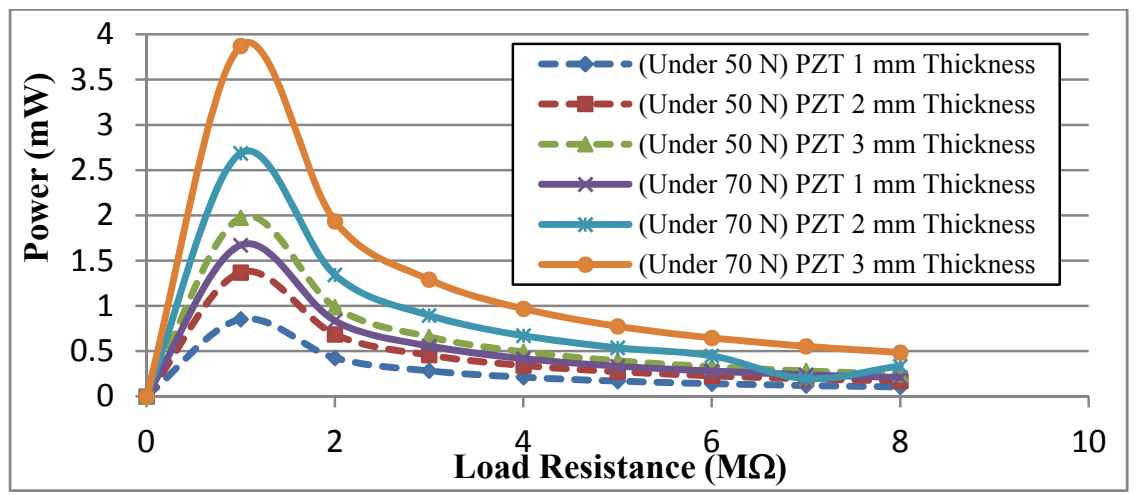

Figure 8: PCT output power with various PZT thicknesses with $0.4 \mathrm{~mm}$ end cap.

\section{Conclusion and future works}

A proposed PCT of dimensions as listed in table 2 has shown the generation capacity of $0.46 \mathrm{~mW}$ of power under $50 \mathrm{~N}$ force across $3 \mathrm{M} \Omega$ load resistance. However, when thicker end cap $(0.4 \mathrm{~mm}$ thickness) is used, it enhanced the force endurance of the end cap and the PCT output power rose up to $0.9 \mathrm{~mW}$. As for the end cap material selection, steel has demonstrated better performance because it enhances the output power and the structure yield strength of the PCT as compared to aluminium material. Based on the simulation studies, it has found that the electrical resistive load and the selected parameters of the PCT had significant effects on the power output form the PCT: increase steel end cap and PZT thickness led to higher power outputs. Several future works such as frequency studies of the PCT performance in an ambient vibration $(20-200 \mathrm{~Hz})$ need to be considered. This is because the PCT can be potentially used in roadways energy harvesting due to its ability to adapt well in high stress and high frequency environment. Since it must be embedded underneath the roadways, the varying vertical stress, strain and vibration exerted on the PCT must be considered. Therefore, the contact pressure between the vehicle tire and the roadway surface need further studies in order to evaluate the energy harvesting ability of the PCT.

\section{References}

[1] H. Zhao, J. Yu, J. Ling, A Comparative Analysis of Piezoelectric Transducers for Harvesting Energy from Asphalt Pavement, 2012. Journal of Ceramic Society of Japan (JCS), 120, pp. 317-323, June 8, 2012.

[2] H. Zhao, J. Yu, J. Ling, Finite Element Analysis of Cymbal Piezoelectric Transducer for Harvesting Energy from Asphalt Pavement, 2010. Journal of the Ceramic Society of Japan (JCS), 118, pp. 909-915, August 19, 2010.

[3] A. Daniels, A. Giuliano, M. L. Zhu and A Tiwari, Modelling, Validation and Design Analyses of a Piezoelectric Cymbal Transducer for Non-Resonant Energy Harvesting, 2013. IEEE International Conference on Green 
Computing and Communications and IEEE Internet of Things and IEEE Cyber, Physical and Social Computing, pp. 1665-1667, 2013.

[4] H. W. Kim, A. Batra, S. Priya, K. Uchino, D. Markley et al., Energy Harvesting using a Piezoelectric "Cymbal" Transducer in Dynamic Environment. Japanese Journal of Applied Physics, Vol. 43, No. 9A, pp. 6178-6183, 7 September, 2004.

[5] H. W. Kim, A. Batra, S. Priya, K. Uchino et al., Piezoelectric Energy Harvesting under High Pre-Stressed Cyclic Vibration. Journal of Electroceramics, Vol. 15, Issue 1, pp. 27-34, September, 2005.

[6] J. Yuan, X. Shan, T. Xie and W. Chan, Energy Harvesting with a SlottedCymbal Transducer. Journal of Zhejiang University Science A, Vol. 10(8), pp. 1187-1190, June 24, 2009.

[7] M. Leinonen, J. Palosaari, J. Juuti and H. Jantunen, Combined electrical and electromechanical simulation of a piezoelectric cymbal harvester for energy harvesting from walking. Journal of Intelligent Material System and Structures, Vol. 25(4), pp. 391-400, 2013. 